LAWRENCE LIVERMORE N A T IO N A L LABORATORY
OPERATION OF

SECOND-GENERATION HCX

DIAGNOSTICS FOR ELECTRON AND

GAS EFFECTS IN MAGNETIC

QUADRUPOLE MAGNETS

A. W. Molvik, P. A. Siedl, F. M. Bieniosek, R. H. Cohen, A. Faltens, A. Friedman, M. Kireeff Covo, S. M. Lund, L. Prost

June 29, 2004 
This document was prepared as an account of work sponsored by an agency of the United States Government. Neither the United States Government nor the University of California nor any of their employees, makes any warranty, express or implied, or assumes any legal liability or responsibility for the accuracy, completeness, or usefulness of any information, apparatus, product, or process disclosed, or represents that its use would not infringe privately owned rights. Reference herein to any specific commercial product, process, or service by trade name, trademark, manufacturer, or otherwise, does not necessarily constitute or imply its endorsement, recommendation, or favoring by the United States Government or the University of California. The views and opinions of authors expressed herein do not necessarily state or reflect those of the United States Government or the University of California, and shall not be used for advertising or product endorsement purposes. 


\title{
Operation of second-generation HCX diagnostics for electron and gas effects in magnetic quadrupole magnets
}

\author{
A. W. Molvik ${ }^{\mathrm{a}}$, P. A. Seidl ${ }^{\mathrm{b}}$, F. M. Bieniosek ${ }^{\mathrm{b}}$, R. H. Cohen ${ }^{\mathrm{a}}$, A. Faltens ${ }^{\mathrm{b}}$, \\ A. Friedman ${ }^{\text {a }}$ M. Kireeff Covo ${ }^{\text {a }}$, S. M. Lund ${ }^{\text {a }}$, L. Prost ${ }^{b}$ \\ Heavy Ion Fusion Virtual National Laboratory, \\ ${ }^{a}$ Lawrence Livermore National Laboratory, Livermore, CA 94550, USA. \\ ${ }^{b}$ Lawrence Berkeley National Laboratory, Berkeley CA 9472-82010, USA
}

\section{Milestone 6/30/04}

Submit a report to OFES on the operation of second-generation HCX diagnostics for electron and gas effects in magnetic quadrupole magnets.

\begin{abstract}
We report the successful development and commissioning of new diagnostics for electron cloud and gas desorption studies on the High Current Experiment (HCX) at LBNL. These measure the time-dependent gas density in a $0.03-0.2 \mathrm{~A} 1 \mathrm{MeV} \mathrm{K}^{+}$ion beam inside of a quadrupole magnet, and the three possible sources of electrons: from ionization of gas, from beam tube walls, and from an end wall where the beam dumps. The accumulation of electrons in the beam is determined by measuring the net charge of the beam with capacitive electrodes, and other diagnostics being developed. These diagnostics are complemented by a suppressor electrode that controls the electron source from an end wall, and clearing electrodes that remove (and measure the current of) electrons from drift regions between quadrupole magnets. Measurements of electron emission coefficients and gas desorption coefficients near grazing angle enable us to infer the magnitude of beam loss needed to produce the measured electron emission and the resulting gas desorption. These new tools provide the capability to explore new areas of electron-cloud effects science, and to make quantitative comparisons with simulation.
\end{abstract}

\section{Introduction}

Electron cloud effects (ECEs) [1] and beam-induced pressure rises [2], that are frequently observed to limit the beam quality in high-energy physics colliders and highintensity rings, are also a concern for future high-intensity heavy ion linear accelerators such as envisioned in Heavy Ion Inertial Fusion (HIF) [3], and heavy-ion-driven highenergy-density physics, where we expect electrons from ionization of background gas to be a possible problem [4-8].

In this report, we describe a time-dependent measurement of the gas density within a $0.03-0.2 \mathrm{~A} 1 \mathrm{MeV} \mathrm{K}^{+}$ion beam in a quadrupole magnet with a field gradient of $\sim 10$ $\mathrm{T} / \mathrm{m}$, and describe how this also measures the ionization source of electrons after a correction; the use of a suppressor electrode to switch, or control, the flow of electrons from the end wall; and the use of clearing electrodes to divert, and measure, electrons from the drift regions between quadrupole magnets. We also measure the current of electrons emitted by beam-tubes. In addition we have other second generation diagnostics in the last two quadrupole magnets of the HCX that measure the accumulation of electrons. Measuring sources and accumulation enables particle balance experiments. 


\section{New diagnostic measures gas density in magnetic quadrupoles}

We determine gas density in the beam by measuring the cold ion current resulting from beam impact on gas These ions are expelled by the positive space-charge beam potential. To measure them, we use a grid-shielded electrode - the grounded grids shield the electrode from the 500 times-greater capacitive current (from the rise and fall of the beam potential at the beam head and tail). This makes it feasible to detect an expelled ion current density of $\sim 0.1 \mu \mathrm{A} / \mathrm{cm}^{2}$.

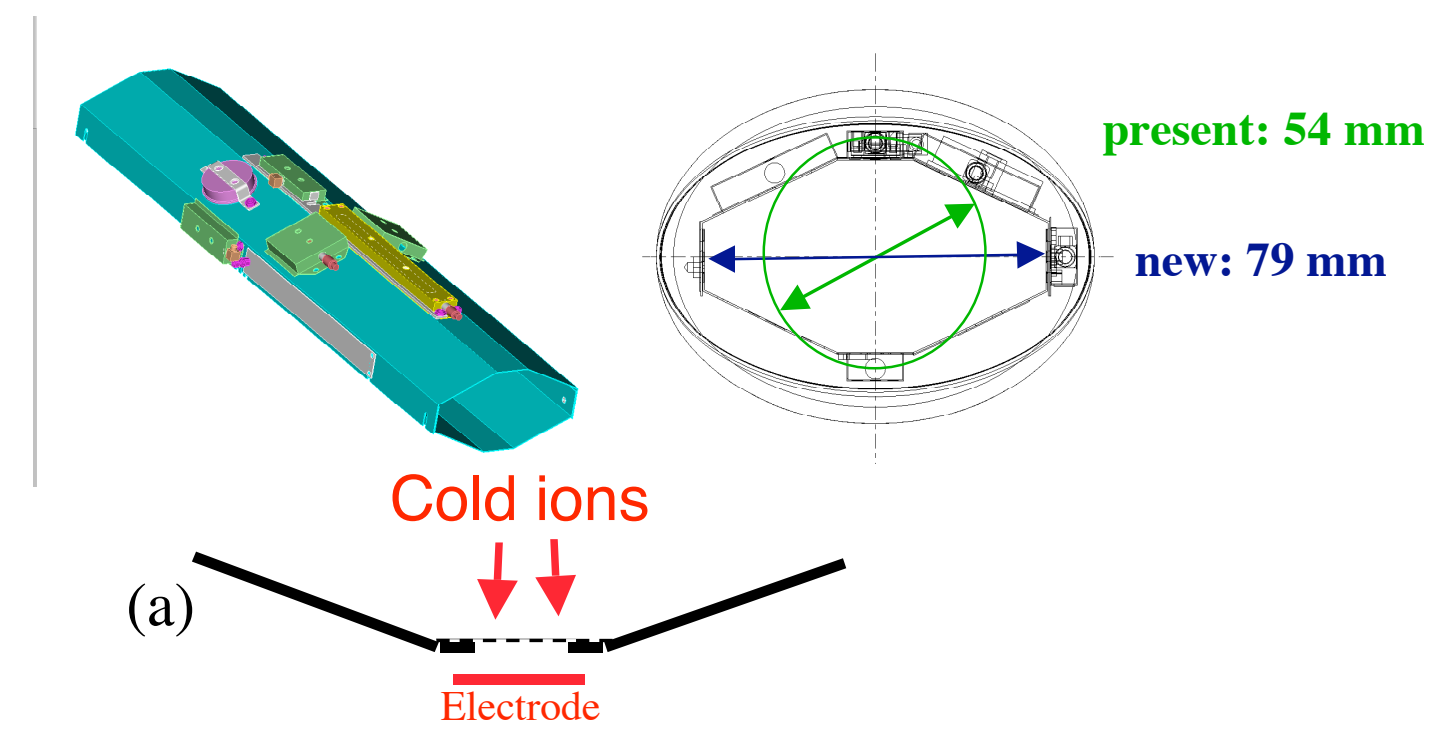

Fig. 1. Grid-shielded electrode measures cold ions from beam impact on gas. The Generation-2 diagnostics are mounted on an octagonal tube that approximates the shape of the elliptical magnet bores, and transmits a much larger (along the major axis) beam, than was possible with the cylindrical diagnostics tube (green above) used for Generation-1 diagnostics.

With an aperture before the quadrupole magnets reducing the beam current to $32 \mathrm{~mA}$, we observe currents to each grid-shielded electrode that ramp from 0.6 to $2 \mu \mathrm{A}$ over the $5-\mu \mathrm{s}$ beam duration. To test whether this signal is dominated by background gas interactions, we injected argon gas between the last two magnets to vary the base pressure. We measure the pressure with ion gauges at the gas injection location and after the last magnet. We found that the current, after the initial fast ramp up, increases with the gas pressure, and that the slope of the current ramp remains constant, after the initial fast rise, increasing by $\sim 1.5 \mu \mathrm{A}$ during each pulse for the first factor of 10 increase in pressure. In Fig. 2, we plot the electrode current after the initial fast ramp up versus the argon pressure from ion gauges (we assumed a linear pressure drop through the fourth magnet to compute the gas density at the grid-shielded electrode location). It is apparent that the current is proportional to the gas pressure, demonstrating that we have achieved a pressure measurement just where we most need it - within the ion beam and inside of a 


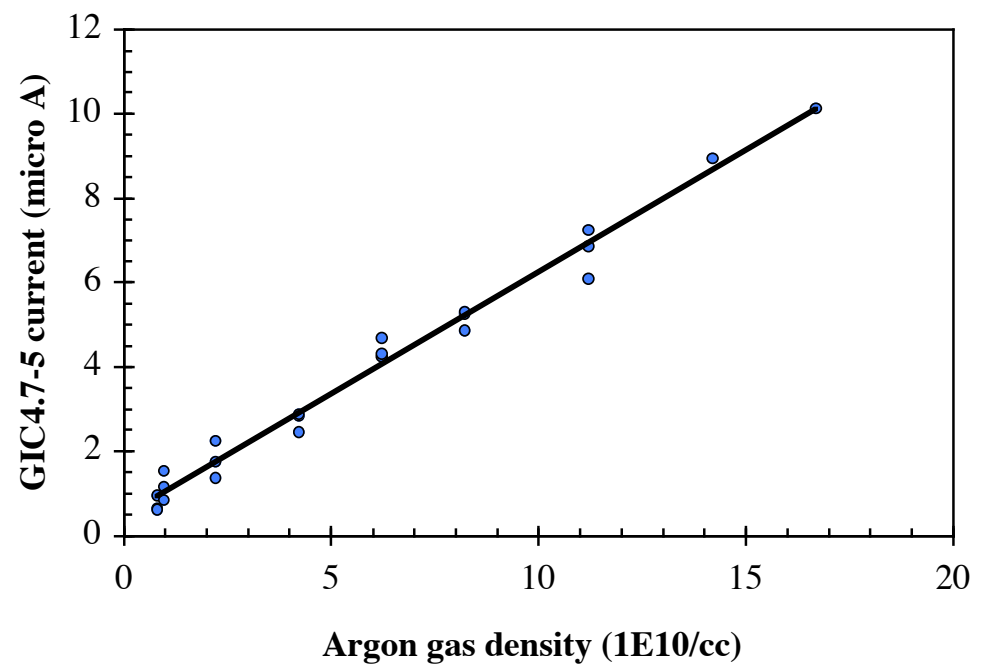

Fig. 2. Expelled cold ion current is proportional to pressure measured with ion gauge.

quadrupole magnet. The gas-density calibration in Fig. 2 is approximate; we can make it precise by calibrating the ion gauges, and by using static gas to eliminate the pressure drop of gas flowing through the magnet bore.

This diagnostic also provides a nearly direct measurement of the generation rate of electrons by beam impact ionization of gas, with a cross section $\sigma_{\mathrm{i}}$. The measured expelled-ion current $I_{i}$ differs from the electron ionization current $I_{e}$ because charge exchange (cross section $\sigma_{\mathrm{x}}$ ) produces a cold ion, but no free electron. Then

$$
\mathrm{I}_{\mathrm{e}}=\mathrm{I}_{\mathrm{i}} \sigma_{\mathrm{i}} /\left(\sigma_{\mathrm{i}}+\sigma_{\mathrm{x}}\right) \approx 0,7 \mathrm{I}_{\mathrm{i}}
$$

In general, charge exchange cross sections are smaller than ionization cross sections, particularly for non-resonant interactions (i.e., the beam ion is not the same element as the gas atom or molecule). Therefore, we expect the electron ionization current to be within a factor of 2 of the expelled ion current.

\section{Suppressor electrode blocks axial flow of electrons}

A suppressor ring, that is $10 \mathrm{~cm}$ diameter and $10 \mathrm{~cm}$ long, was installed surrounding the beam after it exits the last magnet, Fig. 3. It can be biased to $-10 \mathrm{kV}$ to prevent

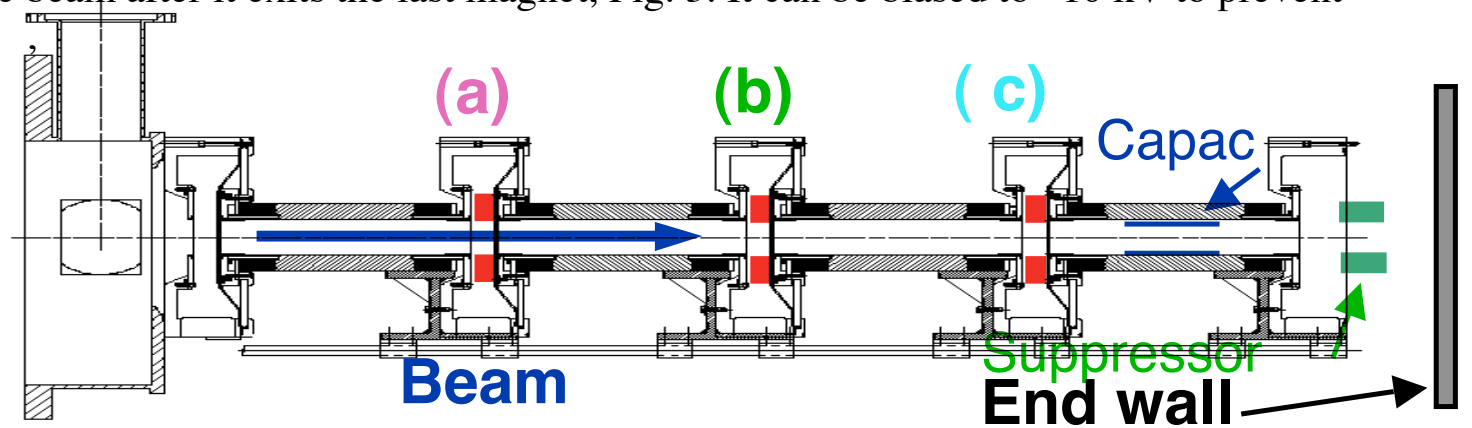

Fig. 3. Four magnetic quadrupole magnets on HCX, each $52 \mathrm{~cm}$ long with diagnostic access between, before and after. Clearing electrodes (red) between magnets, suppressor (green) between last magnet and end wall. The beam propagates to right. 
electrons that are created by beam impinging on the metal end wall from being transported back into the quadrupole magnets. For these experiments, the front plate of a slit scanner is inserted, providing a grounded metal end-wall surface on which the ion beam impinges, generating $\geq 6$ electrons per incident ion [9]. It is located $\sim 30 \mathrm{~cm}$ downstream of the end of the last quadrupole magnet winding. Clearing electrodes were installed between magnets, and will be discussed in the next section. A $28 \mathrm{~cm}$-long capacitive electrode, surrounding the beam and nearly flush to the $3 \times 5 \mathrm{~cm}$ radius magnet bore, was installed axially-centered in the fourth magnetic quadrupole.

The currents to a capacitive electrode in the fourth magnet and to the last clearing electrode-(c) are shown in Fig. 4 with the suppressor electrode biased to 0 and $-10 \mathrm{kV}$, The capacitive electrode shows the expected positive value during the beam head and
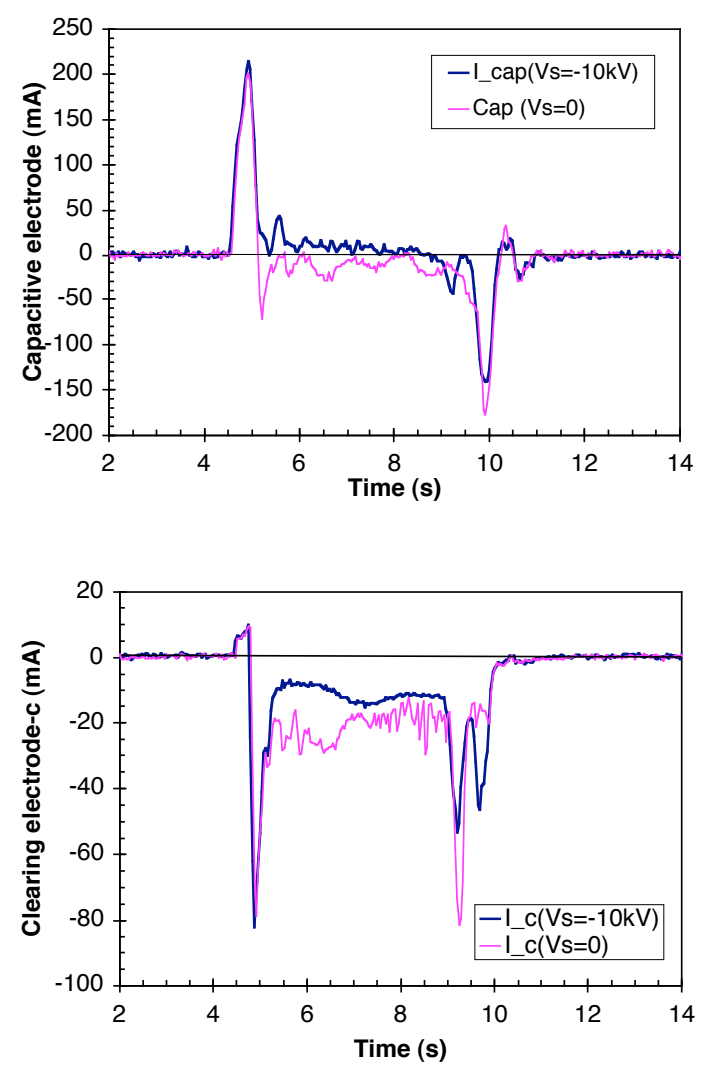

Fig. 4. Current to (a) a capacitive electrode and (b) clearing electrode-c for the suppressor at $0 \mathrm{~V}$ and $-10 \mathrm{kV}$, showing that the suppressor can block the axial flow of electrons.

negative value during the tail, Fig. 4(a), which results from capacitively coupling to the rising beam potential at the head and falling potential at the tail of the beam. When the suppressor is biased to $-10 \mathrm{kV}$, we observe during the nearly flat portion of the beam pulse, that the capacitive current changes from negative to positive (from collecting to emitting electrons) and the positively biased clearing electrode-c current decreases to about half its previous value, indicating that half of the electrons originate at the end wall and half elsewhere - precisely where is left to future investigations. These measurements all indicate fewer electrons in the quadrupole magnets when the suppressor is biased to $-10 \mathrm{kV}$. This, combined with voltage scans showing similar currents for all 
suppressor biases greater than $-5 \mathrm{kV}$, is consistent with the suppressor blocking electron flow from the end wall when biased to $-10 \mathrm{kV}$.

\section{Clearing electrodes sweep electrons from drift regions}

Clearing electrodes were installed in the $5 \mathrm{~cm}$ gaps between quadrupole magnets for the purpose of sweeping electrons from each drift region by applying a positive bias voltage. Each clearing electrode is a circular ring, concentric with the beamline axis with a toroidal inner diameter of $8 \mathrm{~cm}$ and a poloidal diameter of $1.3 \mathrm{~cm}$. This places the electrodes $\sim 1 \mathrm{~cm}$ outside of the magnet bore so that beam halo ions do not strike them.

As mentioned above, the current to clearing electrode-c (between the third and fourth quadrupole magnets as shown in Fig. 3) is strongly affected by the suppressor electrode, decreasing by about a factor of two when the suppressor is biased to $-10 \mathrm{kV}$, Fig. 4(b). This demonstrates that electrons from the end drift upstream through the fourth quadrupole magnet to reach clearing electrode-c when the suppressor is off.

For the shots shown above, the currents to the first two clearing electrodes-a and $-b$ with locations shown in Fig. 3, are unaffected by the suppressor bias. The currents are nearly identical for both electrode-a (Fig. 5) and electrode-b (not shown). This indicates that clearing electrode-c is performing as it was intended to; it removes essentially all electrons flowing upstream at its drift region.

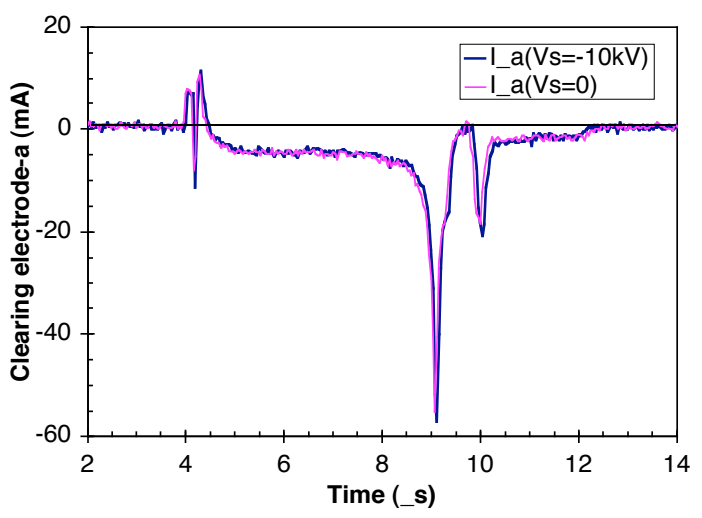

Fig. 5. As above, current to clearing electrode-a is unaffected by the suppressor bias, when clearing electrode-c is biased $+9 \mathrm{kV}$.

We further test the operation of the clearing electrodes by leaving the suppressor voltage at zero to allow electrons to flow into the magnetic quadrupoles, then measuring the current to each clearing electrode as we vary the potential on one clearing electrode at a time. In Fig. 6(a), we plot the current to each clearing electrode as the potential on clearing electrode-c is varied, while the bias voltages on electrodes-a and -b are held constant at $+9 \mathrm{kV}$. Small changes in current are observed for bias voltages between 1 and 4-8 kV. Below $+1 \mathrm{kV}$, the current to electrode-c decreases from $-19 \mathrm{~mA}$ to zero, while that to electrode-b increases by a similar amount, and that to electrode-a stays constant at $\approx-5 \mathrm{~mA}$, because any electrons that get past electrode-c are diverted by electrode- $\mathrm{b}$.

In Fig. 6(b), we vary the bias on electrode-b -, while electrode-c bias is left at zero, electrode-a bias is at $+9 \mathrm{kV}$, and the suppressor bias is still at zero. The behavior is 
analogous to that above, the current to electrode-b remains nearly constant for bias voltages exceeding $+1 \mathrm{kV}$, then decreases from $-7 \mathrm{~mA}$ to zero below $1 \mathrm{kV}$ bias. As the current to electrode-b decreases, that to electrode-a increases by a similar amount, and that to electrode-c remains near zero.

All these results indicate that the clearing electrodes are performing as intended: when biased to a sufficiently high positive voltage, a clearing electrode removes essentially all the electrons in that drift region. For example, if the bias on electrode-c is not high enough, then electrons leak through to electrode-b increasing its current, but electrode- $b$ removes all the electrons from that drift region as intended so that the current to electrode-a remains constant. Similarly, if the bias on electrode-b is lowered, electrons can leak through to electrode-a.
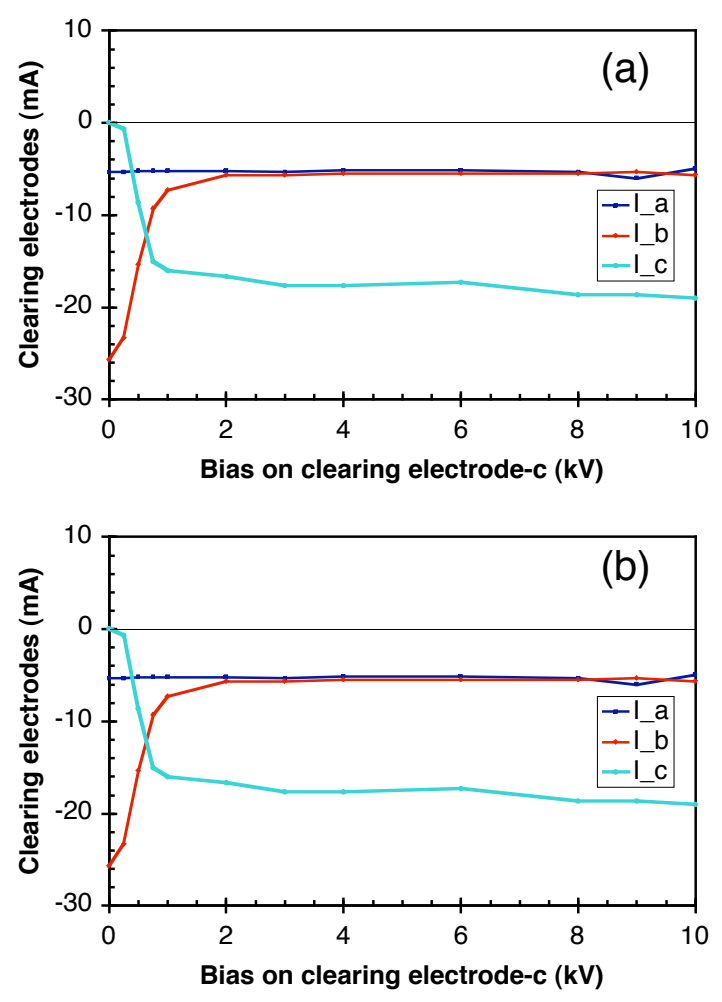

Fig. 6. The currents to clearing electrode $a, b$ and $c$ versus bias voltage on (a) clearing electrode- $c$, and (b) clearing electrode- $b$. With sufficient clearing-electrode bias $(\sim 4 \mathrm{kV})$, electron flow is diverted to the electrode.

\section{Acknowledgements}

We are grateful to Ralph Hipple, William Strelo, Tak Katayanagi, Gary Ritchie, Craig Rogers, and Ed Romero for excellent technical support. This work was performed under the auspices of the U.S. Department of Energy by University of California, Lawrence Livermore National Laboratory under contract No. W-7405-Eng-48, and by University of California, Lawrence Berkeley National Laboratory under Contract DE-AC03-76F00098. 


\section{References}

[1] http://wwwslap.cern.ch/collective/ecloud02/ proceedings/index.html

[2] W. Y. Zhang, "ICFA Workshop on Beam Induced Pressure Rise in Rings," http://www.c-ad.bnl.gov/icfa (2003).

[3] R. O. Bangerter, Phil. Trans. R. Soc. Lond. A 357, 575 (1999).

[4] A. W. Molvik, R. Cohen, A. Friedman, S. Lund, et al., "Initial Experimental Studies of Electron Accumulation in a Heavy-Ion Beam," Proc. Of the 2003 Particle Accelerator Conference, p. 312 (IEEE, 2003).

[5] R. H. Cohen, A. Friedman, S. M. Lund, A. W. Molvik, M. Furman, J.-L. Vay, and P. Stoltz, Proc. Of the 2003 Particle Accelerator Conference, p. 132 (IEEE, 2003).

[6] A. W. Molvik, et. al. HIF-04 (Attached)

[7] R. H. Cohen, et al., HIF-04.

[8] A. W. Molvik, et al., Ecloud04.

[9] A. W. Molvik, M. Kireeff Covo, F. M. Bieniosek, L. Prost, P. A. Seidl, D. Baca, A. Coorey, and A. Sakumi, "Gas desorption and electron emission for $1 \mathrm{MeV}$ potassium ion bombardment of stainless steel," Submitted to Phys. Rev. Special Topics Accelerators and Beams, (2004). 